\title{
Preparing great speeches: A 10-step approach
}

\author{
By Laura A. Sullivan
}

\section{Some belpful tips for making effective presentations}

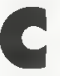
ommunication skills are a standard requirement in library job announcements; speaking skills, however, can be more difficult to acquire and discern. Librarians are faced with a variety of speaking situations daily; we assist users at service desks, discuss problems with colleagues at meetings, present facts to library boards, and express opinions on committees, to name a few. Effective speaking skills are essential in these instances, but when faced with the formal speech or paper presentation many librarians, lacking public speaking experience, are justifiably apprehensive at the prospect.

In working on my own public communication skills, I have relied on my past education, teaching experience, advice from various colleagues, and trial and error. For those testing the water for the first time, the following ten steps are suggested as an easy and organized way to prepare a speech or paper.

1. Know your audience

2. Know the occasion

3. Select a topic

4. Select a purpose

5. Gather potential content

6. Gather more content than actually used

7. Organize content

8. Phrase the speech

9. Prepare visual aids

10. Practice, practice, practice
The ten steps are from Steven Brooks, a former Communications Department faculty member at Northern Kentucky University. I have further developed these steps and hope the information you find here will be helpful to you as you prepare a speech or paper.

1. Know your audience. Whether you are presenting a paper or giving a speech, you need to analyze your audience first and foremost. It is easy to alienate an audience by not examining the characteristics of the group, what they know and what they want to know. Be aware of the audience's attitudes and beliefs in general, toward you and the topic. Consider age, socioeconomic status, and educational level. For example, if you are addressing a veteran group of administrators on a management topic, covering the basics of management would undoubtedly be boring and possibly insulting. There are numerous other factors crucial to analyzing an audience, but the time spent on this background check is necessary for the success of your presentation.

2. Know the occasion. As you scrutinize the audience, think carefully about the occasion. Are you a keynote speaker? Presenting a paper? Introducing a speaker or chairing a panel? Each situation is different and requires preparation tailored to the occasion. Occasion analysis includes looking at room size (i.e., whether there are enough chairs for everyone affects the comfort level of the group which in turn affects its response to your message), the arrangement of space (can everyone see you?), and the acoustics (there's nothing more exasperating than having to strain to hear a speaker). Be conscientious about time limits too-if you 


\section{-ACS Publications Landmarks In Science}

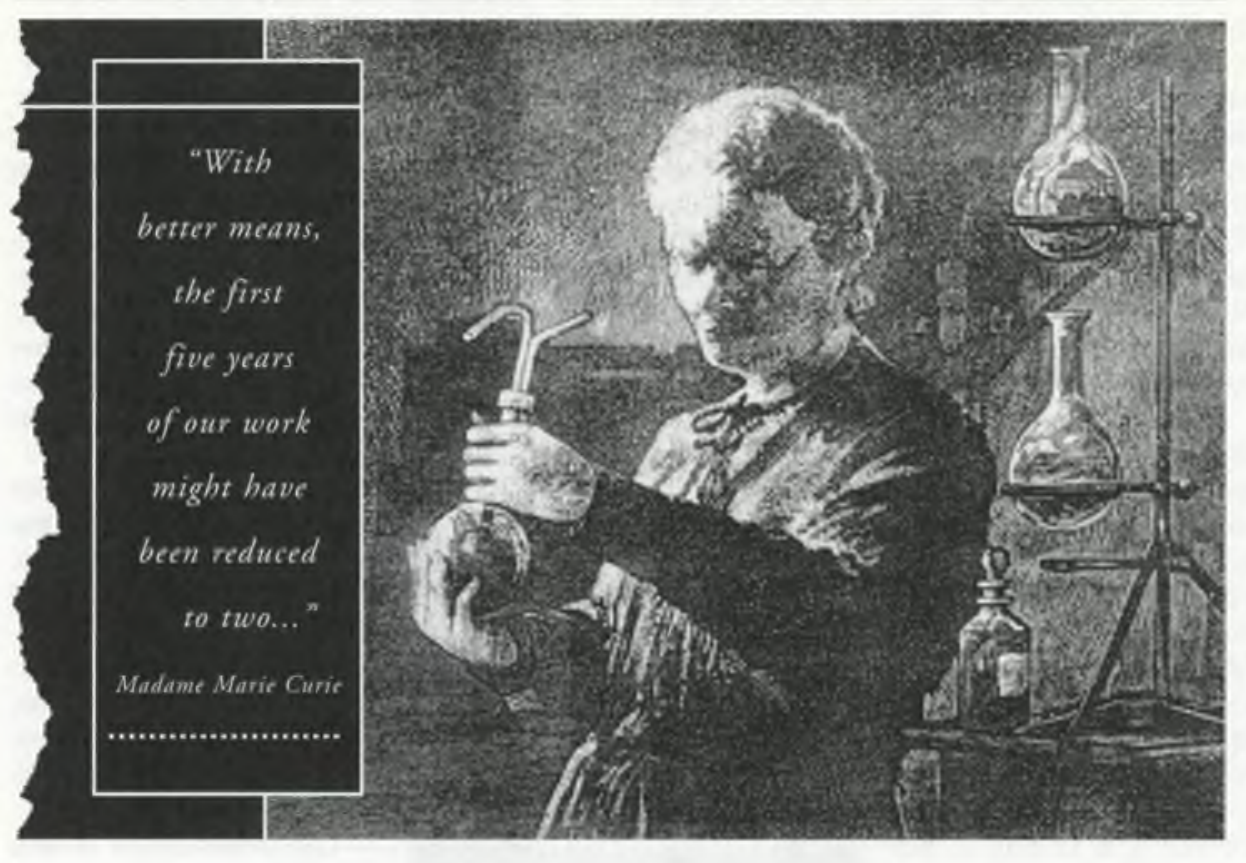

\section{Madame Curie On The Cost Of Science.}

She discovered radium. She coined the word "radioactive" and was the first to suspect it emanated from "aromic energy." Twice winner of the Nobel Prize, her discoveries led to the development of radiation therapy for the treatment of cancer. Yer in spite of her wide acclaim, Madame Curie often had to beg from the wealthy to fund her research. She understood the painful cost of science.

So do we. Since 1876, when the American Chemical Sociery first began to publish scientific journals, we have consistently offered them at affordable subscription rates. ACS journals cost, on average, about $50 \%$ * of the price charged for competitive publications in our discipline. And we are committed to continuing this tradition, withour compromising the quality of science we publish.

Today, the chemical sciences are advancing at a staggering rate. And we've increased our page budgets and our publication frequencies to keep pace with the increased flow of critical research. Yet the price of our journals remains comparatively low, especially when you consider the quantity, timeliness and exceprional value of the information. Write or fax ACS Publications and we'll send you the most recent cost analyses for our publications. Please include your suggestions about how we can serve you better.

We're working hard to provide tomorrow's landmark scientists with the means to afford today's research.

\section{ACS 피 PULICATIONS \\ Essential Renources for the Chemical Sciences}

1155 Sixteenth St. NW, Washington, D.C 20036 USA

Let us hear from you. Fax (202) 872-6005

Fes, please send me your recent cost analyses.
My suggestions are included on a separate sheet.
Name
Library

"According to a report in the April 15, 1994 issue of Library Journal, the chemical sciences had an average price per journal of $\$ 1,106$. 
are allotted 15 minutes, then prepare your speech or presentation accordingly. Also, make sure your message matches the occasion. It would be inappropriate, for example, to speak about a serious topic at a happy event.

3. Select a topic. Selecting a topic can sometimes occur first, stemming from the audience and occasion, as in the case of a paper being accepted for a conference. If you need to pick a topic, however, be sure it is one that is interesting to you. It is also a good idea to be a little more knowledgeable about the subject than your audience, but interest is crucial. If you do not have enthusiasm for the subject matter, neither will your audience.

4. Select a purpose. For this step, determine the general purpose of your speech or presentation. Are you informing, presenting, or entertaining? Beyond the general purpose, decide on a specific purpose, what you want your audience to specifically think or do (e.g., I want my audience to understand the three benefits of holding a faculty workshop on preparing library assignments). It is helpful at this stage to write down the central idea or thesis statement of your talk as well (e.g., library censorship is increasing).

5. Gather potential content. If you are presenting a paper, you have already done this step. If not, this is the research phase where you gather information through printed sources, interviews, discussion with others, and your own expertise.

6. Gather more content than actually used. Sort through your material choosing only the strongest and best material for your talk. This step allows you the luxury of editing and, if need be, recognizing any information gaps that need to be filled.

7. Organize content. The importance of this step cannot be stressed enough, for both speeches and paper presentations. Many presenters do not realize that presenting a paper does not mean the paper is read, word for word, at breakneck speed. Rather, the "information has to be recast for the new medium. Don't be bound by the flow of your paper."2 This means organize your ideas based on the audience, occasion, and purpose of your presentation.

Follow the standard organizational format of introduction, body, and conclusion, which translates into the standard public speaking formula:

- Tell them what you're going to tell them;

- Tell them;

- Tell them what you've told them. ${ }^{3}$

Outline the body of your talk first, limiting it to three or four main points with sufficient supporting material to back up those points. Too much information can lose an audience; well-organized key points help an audience remember them and allow for easy note-taking. Also, if presenting a paper, your goal is to whet the appetite of the audience with key ideas so they will want to get a copy of the full paper to read at a later time. ${ }^{4}$

After you have outlined the body of your speech or paper, prepare the introduction and conclusion. Your introduction should start out with an attentiongetter which can be an anecdote, a quotation, a question, a joke, or whatever is appropriate for the topic and audience.

The introduction is also your opportunity to build rapport between you and the audience; tell them why your speech or paper is relevant to them and that you are glad to be speaking to them. A colleague related to me an opening remark by a speaker which did not serve to build rapport between her and the audience, even though she probably intended it to. The speaker said, in essence, "I've been to a hundred of these and, to tell you the truth, I really don't want to be here; my feet hurt; and I don't know what I'm going to say, but we'll get through this together." Please, treat your audience as if they are guests in your home.

Once you've told your audience why they should want to listen to you, lead into your talk by briefly previewing the major points to be covered in your speech (tell them what you're going to tell them).

The conclusion should include the summary of the main points (tell them what you've told them) and a final statement that leaves the audience with something to think about or remember (this will depend on the purpose of your speech).

For your talk, I suggest you write the main ideas of your introduction, body, and conclu- 
sion on $3 \times 5$ note cards that are numbered (in case you drop them). Many speakers write delivery cues on the cards, i.e., "slow down," "emphasize this word," "look at audience." You can also indicate transitions on the cards so you will move smoothly from idea to idea. Overall, be sure your note cards are just that - easyto-read notes on easy-to-handle cards-and not the speech written in full.

8. Phrase the speech. The previous steps involved preparing the message; now you are ready to work on delivering the message. Usually, a type of clelivery most appropriate is the extemporaneous delivery. With extemporaneous speaking, you are thoroughly prepared and practiced, but the exact wording of the speech is determined at the time you actually speak the words. You want to avoid memorizing your talk; instead, know your key ideas and translate them into words as you speak. This means you have to think about what you are saying as you are speaking. Each time you practice, you may say your speech a little bit differently, but this allows flexibility and the chance to adapt to your audience if needed. Speaking extemporaneously can be difficult to achieve at first, but this style of delivery creates spontaneity, which can affect the receptivity of your audience to you and your ideas.

9. Prepare visual aids. Visual aids, if appropriate for your speech or presentation, can help your audience remember your points and clarify information. Speech textbooks usually emphasize the following when covering visual aids: make sure the audience can see the visual aid; show the visual aid only when you are referring to it; and talk to the audience, not to the visual aid. Also, practice with the visual aid; using visual aids can add to the length of a talk and can cause you to become flustered if you run into difficulties. Additionally, if you have audience handouts, distribute them at the end of your talk if possible. An audience's attention can shift easily to a handout instead of staying focused on you.

10. Practice, practice, practice. Practicing your presentation or speech contributes directly to your success as a speaker. As you practice, consider both your verbal and nonverbal delivery. Vocal delivery includes volume, rate, pitch. Strive for vocal variety which is the variation of these elements-loudness/softness (volume), fastness/slowness (rate), highness/lowness (pitch). An expressive voice will engage an audience; a monotonous, flat voice will lose one. Also, remember that nonverbal delivery carries as much weight as verbal. Eye contact with your auclience is crucial, and this means actually looking at audience members. Hamilton Gregory says to look at the audience 95 percent of the time in a friendly, sincere way, using the other five percent of the time to look at your notes. ${ }^{5}$ As for posture, don't slouch, and avoid shifting your weight from foot to foot.

Also, movement is fine, but only if it is controlled-your audience does not want to feel it is at a tennis match. Gesturing can be an effective element to your talk, but only if it's controlled as well. Many speakers indicate on note cards when to gesture or move in order to reinforce a point.

There are certainly other elements of verbal and nonverbal delivery to investigate when practicing your speech or paper. Your goal is to sound spontaneous and feel comfortable, so time spent practicing is necessary. It is a good idea to practice in a situation as close to the real one as possible, and in front of friends or with a tape recorder.

Even if you follow these ten steps, you probably will experience some nervousness before or during your talk. This "energy" is an asset and evidence that you care about the quality of your presentation. However, if you have prepared well and practiced enough, you will lessen your apprehension considerably. Also, think positively as you prepare, rehearse, and actually deliver your message. Positive thoughts can make a difference in the quality of your speech or presentation.

If you keep these ideas in mind and follow the ten steps, you can have a successful (and relatively painless!) speaking experience.

\section{Notes}

1. "Ten Steps" in preparing a speech was part of a lecture by Dr. Steven Brooks in his class, "Teaching of Oral Communication," 1986.

2. Donata Renfrow and James C. Impara, "Making Academic Presentations-Effectively!" Educational Researcher 18 (March 1989): 20-21.

3. Clare Martin, "A Woman's Place Is on the Platform," Assistant Librarian 80 (July 1987): 100-101.

4. Renfrow and Impara, "Making Academic Presentations," 21.

5. Hamilton Gregory, Public Speaking for College and Career (New York: Random House, 1987), p. 285. 


\title{
Since $1879 \ldots$
}

\section{Books}

\section{Periodicals}

Technology

Service

Tradition

Reliability

The BLACKWELL Companies

\author{
B. H. Blackwell
}

Blackwell North America

Blackwell Periodicals

Readmore

Readmore Academic Services

Oxford $\bullet$ Lake Oswego, OR • Blackwood, NJ • New York $\bullet$ Toronto 